\title{
A Review of Methane Gas Detection Sensors: Recent Developments and Future Perspectives
}

\author{
Tahani Aldhafeeri ${ }^{1}$, Manh-Kien Tran ${ }^{1}\left(\mathbb{D}\right.$, Reid Vrolyk ${ }^{1}$, Michael Pope ${ }^{1,2}$ \\ and Michael Fowler $1, *$ (D) \\ 1 Department of Chemical Engineering, University of Waterloo, Waterloo, ON N2L 3G1, Canada; \\ tahani.aldhafeeri@uwaterloo.ca (T.A.); kmtran@uwaterloo.ca (M.-K.T.); reid.vrolyk@uwaterloo.ca (R.V.); \\ michael.pope@uwaterloo.ca (M.P.) \\ 2 Waterloo Institute for Nanotechnology, University of Waterloo, Waterloo, ON N2L 3G1, Canada \\ * Correspondence: mfowler@uwaterloo.ca; Tel.: +1-519-888-4567 (ext. 33415)
}

Received: 18 June 2020; Accepted: 4 July 2020; Published: 6 July 2020

\begin{abstract}
Methane, the primary component of natural gas, is a significant contributor to global warming and climate change. It is a harmful greenhouse gas with an impact 28 times greater than carbon dioxide over a 100-year period. Preventing methane leakage from transmission pipelines and other oil and gas production activities is a possible solution to reduce methane emissions. In order to detect and resolve methane leaks, reliable and cost-effective sensors need to be researched and developed. This paper provides a comprehensive review of different types of methane detection sensors, including optical sensors, calorimetric sensors, pyroelectric sensors, semiconducting oxide sensors, and electrochemical sensors. The discussed material includes the definitions, mechanisms and recent developments of these sensors. A comparison between different methods, highlighting the advantages and disadvantages of each, is also presented to help address future research needs.
\end{abstract}

Keywords: methane detection; methane sensors; optical sensors; electrochemical sensors; calorimetric sensors; pyroelectric sensors; semiconducting oxide sensors

\section{Introduction}

Methane $\left(\mathrm{CH}_{4}\right)$, a flammable gas that lacks both odour and colour, is the primary component of natural gas. It is used as a fuel worldwide as a source for electricity generation and heating and plays a significant role in driving climate change. Methane is a powerful greenhouse gas (GHG) with a global warming potential 28 times greater than carbon dioxide $\left(\mathrm{CO}_{2}\right)$ over a 100-year period [1]. With the onset of the industrial revolution, atmospheric methane concentration has increased dramatically from approximately 800 parts per billion (ppb) in the early 1900s to upwards of $1800 \mathrm{ppb}$ in 2016 [2]. This increase can be attributed primarily to the following anthropogenic sources of emission: landfills, animal waste management systems, coal mining, petrochemical exploration, power transformers and oil and gas distribution and production facilities [3]. In addition, methane gas is flammable and can be explosive if its concentration reaches 5 to $15 \%$ in an enclosed area [4]. Despite its negative impacts on the environment, natural gas is coveted for its abundance and clean burning process, and therefore, will continue to be used widely in the future [5]. It replaces coal, especially in the USA power field, due to the lower $\mathrm{CO}_{2}$ emissions compared to coal in the combustion process and the lower production cost [6]. Moreover, it is predicted that natural gas will be the second most employed energy source in the future [7]. Maroufmashat et al. [8] highlighted the importance of natural gas in the transition to a fossil-free economy. The authors discussed different approaches to the power-to-gas solution including electricity generation, energy storage systems and transportation energy systems. 
Since the use of natural gas in the future is inevitable, solutions to reduce methane emissions should be developed. Methane emissions can be the result of equipment malfunctions such as pipe cracking or an unsealed pipe joint, release practices such as flaring, or accidental releases during normal transportation, storage, and distribution activities [9]. In addition, methane emissions from wells can be caused by a loss of natural gas integrity through faulty sealed well casings, cement deterioration of the wellbores, or lateral migration along adjacent geological formations [10]. The Conference Board of Canada found that methane released by leakage through wells and equipment contributes $8.5 \%$ of GHG emissions in Canada [11]. Olmer et al. [12] reported that methane emissions from global shipping of liquified natural gas accounts for more than $5 \%$ of the 932 million tonnes of $\mathrm{CO}_{2}$ equivalent in total. Ingraffed et al. [13] found that the average methane emissions from oil and gas wells in Pennsylvania reach 55,600 tonnes/year. Wisen et al. [14] studied the methane leakage in northeastern British Columbia where the shale gas basins are located and estimated that 75,000 metric tonnes/year of emissions were released.

The Canadian Government has set a methane emissions reduction target of 40-45\% by 2025 relative to the 2012 level. A 45\% reduction in methane emissions corresponding to 56 billion cubic feet of methane gas is expected to protect the environment and benefit the economy by a recovery of 251 million Canadian dollar (CAD) per year [15]. A solution to reduce methane emissions is to prevent methane leakage from transmission pipelines and other activities from gas and oil production. In order to detect leaks in the natural gas infrastructures, methane sensors that are reliable and cost-effective need to be developed. This would allow polluters and policy-enforcers to detect and resolve leaks in a timely manner. Therefore, a variety of methane sensors, each implementing a different technology, have been developed. Depending on the type of material and technology, the sensors are built with, they are classified as follows: optical sensor, capacitance-based sensor, calorimetric sensor, resonant sensor, acoustic-based sensor, pyroelectric sensor, semiconducting metal oxide (SMO) sensor, and electrochemical sensor.

Several research works have been conducted to help develop and improve different types of gas sensor. Lu et al. [16] discussed the advantages, limitations, applicable occasions, and performance of the existing detection methods used in oil and gas pipelines, including sensors, lidars, and radars among some other technologies. Dey et al. [17] provided a detailed study of SMO gas sensors and a detailed comparison of SMO gas sensors with other gas sensors, especially for ammonia gas sensing. Wu et al. [18] presented a comprehensive and systematic overview of graphene-based optical gas sensors regarding various aspects including sensing principles, properties, fabrication, and implementation. However, a comprehensive review of different sensors specifically used to detect methane has not been provided. Since the type of gas also affects the working mechanism of most sensors, methane sensors can have different properties from other gas sensors. This paper provides a comprehensive review of five different types of methane sensor, which are optical sensors, calorimetric sensors, pyroelectric sensors, semiconducting metal oxide sensors, and electrochemical sensors, as they are more common for methane detection. The basic definitions, working mechanisms, advantages and disadvantages of each sensor are discussed. Recent research works on the sensors in terms of novel material testing and design improvement are also reviewed. Finally, a comparison between all the discussed methane sensors is provided to highlight opportunities for future development.

The rest of this paper is organized as follows. Sections 2-6 introduce and discuss optical sensors, calorimetric sensors, pyroelectric sensors, semiconducting metal oxide sensors, and electrochemical sensors, respectively. Section 7 provides a comparison of the reviewed sensors and some future perspectives. Finally, concluding remarks are given in Section 8.

\section{Optical Sensors}

Optical gas sensors detect changes in visible light or in electromagnetic waves that result from an interaction of the analyte with the receptor part [19]. In measuring emissions, scattering or absorption are the main mechanisms of the optical gas sensor [20]. However, infrared (IR) absorption spectroscopy 
is the most common technique used for optical methane sensors, where the wavelength and the absorption intensity of mid-IR light are measured to determine the qualitative identification of the molecules [21]. Certain chemical bonds have specific absorption band wavelengths making it possible to identify the gas by mid-IR absorption sensors. By this principle, methane gas can be detected by diode laser optical sensors at wavelengths of 2.3 and $3.26 \mu \mathrm{m}$, which are the strong absorption lines of methane [22]. Methane also has weak absorption lines at 1.33 and $1.66 \mu \mathrm{m}$, which are in near-IR wavelength regions [23]. Figure 1 shows an example of a working optical methane gas sensor, which consists of a light source to provide the mid-IR light, a tube to hold the gas sample being tested, and an optical spectrum detector. The light source emits mid-IR light which reflects along the inside walls of the tube as it passes through the gas. The gas molecules that vibrate within the IR frequency range would then absorb the IR radiation from the light. After passing through the gas, the IR light reaches the optical spectrum detector which produces a measurement of the output intensity of the emitted light. Using the input and output intensity of the light source and the length of the travelled distance, a value for the effective absorption coefficient of the gas can be determined. The effective absorption coefficient is used to identify whether methane is present in the gas sample [24].

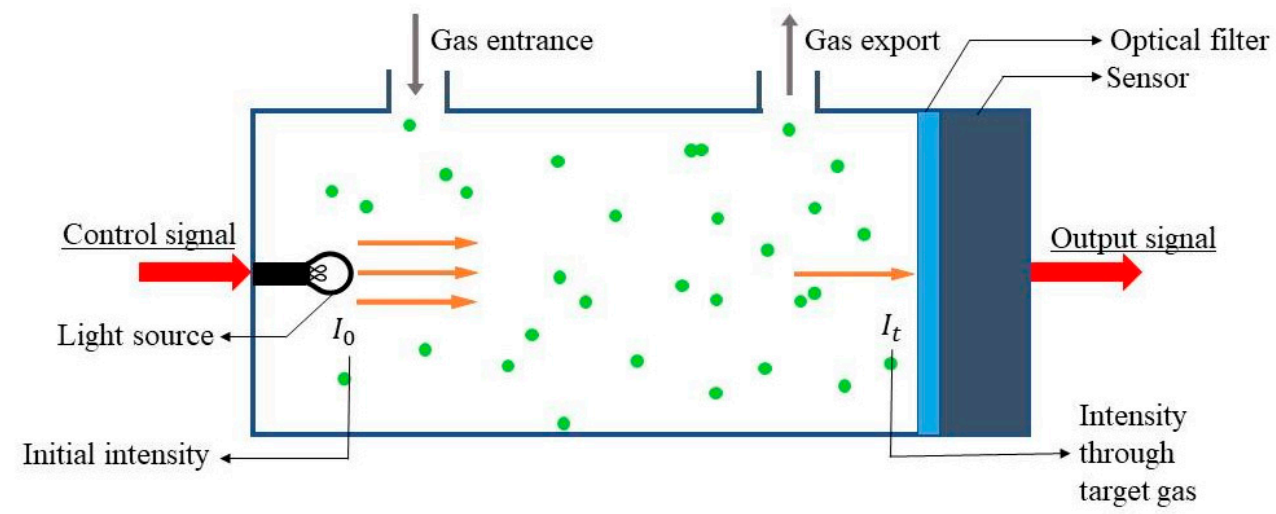

Figure 1. Gas detection by infrared absorption spectroscopy.

The optical methane sensors on the market are often based on IR absorption spectroscopy, which include in situ (on-site) sensors or remote sensors. An example of an in situ optical methane sensor is a mobile methane sensor mounted on a vehicle to detect methane leaks along the natural gas pipelines. When the sensor detects methane, audio and visual signals are sent to a display inside the vehicle to alert the operator. The remote methane sensors also detect methane using IR spectroscopy but without the need for a gas sample. These sensors survey a specific area and relay signals through an optical fiber network when methane is detected [25]. Even though there are many optical methane sensors on the market, they are still being developed and tested to optimize the sensitivity and response time. Sensitivity is important because the sensor needs to detect methane at low concentrations. Response time is also critical because methane leaks need to be detected quickly.

Wolfebeis et al. [26], Shemshad et al. [27], and Yin et al. [21] studied the advantages and disadvantages of near-infrared methane sensors based on non-chemical fiber optics, tuneable diode laser, and chemical fiber optics, respectively. One of the advantages of optical methane sensors is that they use a non-destructive method of detecting methane, since absorption spectroscopy is a physical analysis method, and not a chemical reaction. The components of sensors, hence, are not significantly affected by degradation, which minimizes the maintenance costs for the sensor operation [20]. Another advantage of optical methane sensor is their immunity to electromagnetic interference which can sometimes cause problems for other types of sensors [28]. They also have the ability to operate in the absence of oxygen, pre-treatment or a build-up of gas sample [29]. However, optical sensors have several disadvantages that hinder their potential for wider industrial use. Even though absorption spectroscopy has lower costs than other forms of analysis such as mass 
spectroscopy or gas spectroscopy, its operating costs become higher when used for detection in a larger setting [30]. Another disadvantage of optical sensors is the lack of significance and distinctiveness of the methane optical absorption region, because methane has absorption bands in the same absorption wavelength regions as many other hydrocarbons such as ethane and propane [24].

\section{Recent Research Developments}

There have been some studies focusing on the improvement of optical methane sensors. Yang et al. [28] enhanced the sensitivity of a long-period fiber grating (LPFG) optical methane sensor using high refractive index polycarbonate/cryptophane A overlay deposition. Altering the overlay thickness caused the resonant wavelength to shift, and at the optimal thickness, a drastic shift in resonant wavelength was observed, which led to a significant improvement in the sensor's sensitivity. Dong et al. [31] developed a cavity-enhanced approach for a Fabry-Perot cavity (FPC) sensor to improve gas measurement accuracy. The technique involved recording the transmission maxima of the cavity modes by scanning the cavity length at every laser frequency. It was found that the FPC sensor, with the new technique integrated, was able to achieve a methane detection sensitivity of 0.7-2.9 part per million by mass (ppm-m). Zhang et al. [32] investigated an optical fiber-based methane sensor based on graphene-doped stannic oxide. The sensor was fabricated by coating side-polished optical fibers with thin graphene-doped tin oxide films, and the light source of the optical spectrum was set to a wavelength of $1550 \mathrm{~nm}$. Different concentrations of methane were applied to measure the output light intensities of the optical fibers. As the concentration of methane increased, the conductivity of $\mathrm{SnO}_{2}$ and the refractive index increased. This resulted in an increase of the output light intensity and a decrease in the absorption coefficient. The final results indicated that the intensity and stability of the output light intensity, as well as the reliability, reproducibility, and sensitivity of the sensor, were improved by the adding graphene doped $\mathrm{SnO}_{2}$. Zheng et al. [30] developed a mid-IR methane sensor without pressure control, using a continuous-wave inter-band cascade laser to target a methane absorption line located at $3038.5 \mathrm{~cm}^{-1}$. The sensor was found to function normally with methane samples at 1.0, to 2.1 part per million by volume (ppm-v) concentration levels as the pressure changed from 25 to 800 Torr. Tombez et al. [33] used the IR tunable diode-laser absorption spectroscope with chip-scaled silicon photonic integration to develop compact, cost-effective, and versatile gas sensors. The authors used a near-IR $(1650 \mathrm{~nm})$ light from a distributed-feedback laser and an uncooled InGaAs detector, with a high-index contrast nanoscale silicon waveguide to probe ambient methane, yielding sub-100-ppm-v detection limits. Campanella et al. [34] developed an FPC methane sensor using the principle of absorption-induced redirection of light propagation in coupled resonant cavities. The proposed architecture consisted of a Fabry-Pérot (FP) resonator coupled with a fiber ring resonator, operating in the near IR. The variation of the methane gas concentration in the FP region, which changed the absorption coefficient of the FP, allowed the redirection of the light propagation in the fiber ring resonator. A sensitivity of $0.37 \pm 0.04[\mathrm{~dB} / \%]$, defined as the contrast ratio between resonant modes at different outputs, in a range of methane concentration between $0 \%$ and $5 \%$, was achieved. Ismaeel et al. [35] designed a simple, low-cost, and compact all-fiber methane sensor consisting of a D-shaped cross section optical fiber in between two fiber Bragg gratings. The main improvement in this work was the coating of the fiber with a Teflon layer that was doped with cryptophane which has an affinity towards methane gas. The sensor achieved a high sensitivity of $0.16 \mathrm{~nm} / \mathrm{ppm}-\mathrm{m}$ with a response time of $4 \mathrm{~s}$. Hollow-core photonic crystal fiber (HC-PBF) is a promising technology that has been investigated recently, where the gas can be stably filled into the hollow core, enabling a more efficient light-gas interaction [36,37]. HC-PBF-based photothermal spectroscopy can detect a wide range of gases including $\mathrm{CH}_{4}, \mathrm{H}_{2} \mathrm{~S}, \mathrm{CO}_{2}, \mathrm{CO}, \mathrm{NH}_{3}$, etc., but the response time and sensitivity of the sensor can be affected by the HC-PBF length. 


\section{Calorimetric Sensors}

Calorimetric sensors are used to detect methane and other combustible gases in various applications in coal mines, petroleum drilling and processing fields, and landfills $[38,39]$. There are three types of calorimetric gas sensors, which are the catalytic gas sensor, adsorbent-based gas sensor, and thermal conductivity gas sensor. The calorimetric gas sensor often consists of a temperature sensor, a catalytic combustor, and a heater device. The working mechanism of the calorimetric sensor is based on the principle that a chemical reaction or a physisorption process absorbs or releases heat as shown in Figure 2. The most important part in the calorimetric sensor is the material that interacts with the gas. A surface layer is often utilized as a catalyst for the combustion reaction to reduce combusting temperature. Platinum $(\mathrm{Pt})$, palladium $(\mathrm{Pd})$, and rhodium $(\mathrm{Rh})$ are the most used catalysts in calorimetric gas sensors [40]. Common calorimetric sensors use catalyst-coated platinum or palladium coil, also known as the pellistor [41]. For methane, the oxidation of the gas when in contact with the catalyst is an exothermic reaction which releases heat [42]. This results in a temperature change of the catalytic surface, due to the chemical reaction, which is employed by the calorimetric sensors to produce a sensing signal. Thermal equilibrium is the first state, where the analyte and temperature signals are absent. The second state is the absorption of the analyte by the polymer, and the temperature of the polymer increases. Finally, the signal returns to zero because of the concentration equilibrium and constant enthalpy.

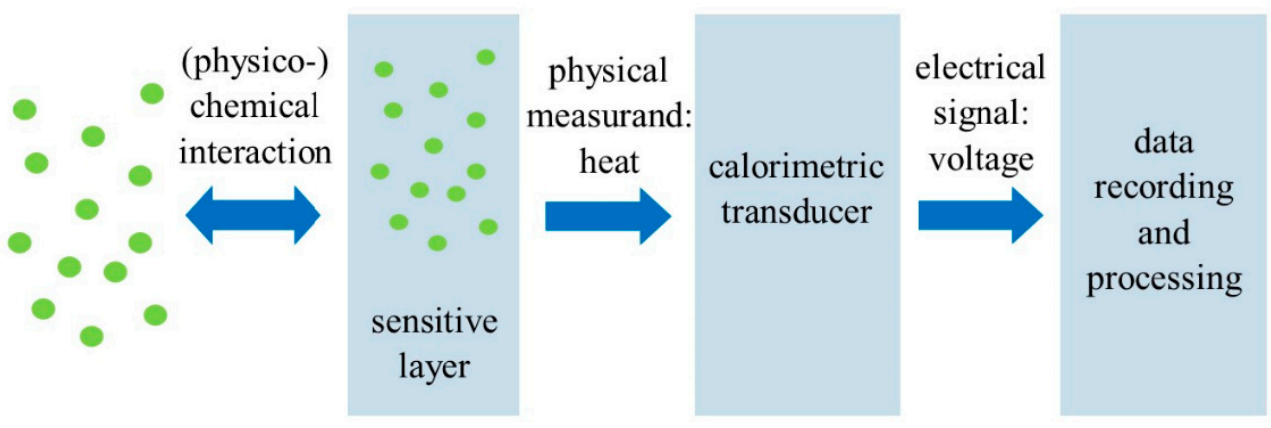

Figure 2. Calorimetric gas sensor principle.

Calorimetric gas sensors have advantages such as low cost, simplistic design, and easy to manufacture [18]. Environmental factors such as temperature, pressure and exposure to water vapour influence the catalysts performance without any major consequence, which allows the sensors to operate in harsh environmental conditions [43]. Additionally, they are portable and have good selectivity for methane and other volatile hydrocarbons [44]. However, if there is a small change in the enthalpy due to a change in the analyte concentration, the calorimetric gas sensors might have poor performance and inaccurate detection. They are also susceptible to cracking, catalyst poisoning and oversaturation from a high concentration of gas [45]. Poisoning compounds can deactivate the sensor by permanently reducing its sensitivity. Some other disadvantages include high power consumption, the inability to operate long-term and the need for elevated temperatures [46].

\section{Recent Research Developments}

The only calorimetric catalytic methane sensor available on the market is quite selective and accurate with approximately $\pm 5 \%$ error [47]. A strategy to prevent incorrect readings, due to the possible loss of sensitivity, is to calibrate the sensor to a known concentration of methane. A relative response factor can be obtained to determine if there is a loss of sensitivity, and the sensor can then be recalibrated to adjust for the sensitivity variation. In the 1990s, Krebs et al. [48] were able to detect methane and other gases with a micromachined calorimetric sensor at $400{ }^{\circ} \mathrm{C}$ using a thin palladium film as a catalyst. More recently, Bíró et al. [49] used a pellistor-type calorimetric methane sensor with $\mathrm{Pt}$ catalyst deposited on a porous anodic aluminum oxide that was located on top of a micro heater. 
Their sensor detected methane and propane concentrations of between $20 \%$ and $100 \%$ of their lower explosion limit. Heater fracture and lower stability of the catalyst are the main disadvantages of the sensor due to the high operational temperature $\left(570 \pm 10^{\circ} \mathrm{C}\right)$ and the frequently applied pulse mode operation. Park et al. [40] developed a novel miniaturized calorimetric sensor with a dual-catalyst structure by integrating different catalysts on the hot $\left(\mathrm{Pd} / \theta-\mathrm{Al}_{2} \mathrm{O}_{3}\right)$ and cold $\left(\mathrm{Pt} / \alpha-\mathrm{Al}_{2} \mathrm{O}_{3}\right)$ ends of the device. The sensor successfully detected methane with concentrations ranging between 200 and 2000 ppm-m at temperatures of $100-400{ }^{\circ} \mathrm{C}$. Alpert et al. [50] found that the sensor can suffer from errors due to pulse shape variation from the detector nonlinearity and readout dependence on the sample arrival times. The authors then developed a processing method that uses a single-value decomposition for single-pulse separation to construct a model that can account for pulse shapes with varying amplitude and arrival time, making it suitable for detecting near-coincident events. The results showed the required performance specifications of the sensors were reduced. Gardner et al. [51] used 3D multi-physics finite element modeling to optimize the geometry of a calorimetric thermal flow sensor. The optimal distance between the heating resistor and the temperature sensing diodes within the sensor was determined, along with the heater and membrane geometries, depending on the sensor applications. To achieve lower power consumption, Shen et al. [52] designed and tested a new intelligent methane sensor using a low-power microelectromechanical system (MEMS) catalytic methane cell, pulse supply mechanism and low-power waste circuit. It was observed from the test that the new sensor achieved low-power consumption and good methane detection. This could potentially solve the problem of high power consumption of traditional catalytic sensors with single circuit power supply.

\section{Pyroelectric Sensors}

Pyroelectric sensors use electromagnetic radiation detection at a certain wavelength. They are often used as fire alarms, laser detectors, thermal analyzers, or gas analyzers $[53,54]$. The pyroelectric sensor converts electromagnetic or thermal energy into electrical energy [55]. It is a non-contact thermal sensor that works at room temperature [56]. The sensor employs the use of a dielectric substrate that is sandwiched between two electrodes. An electric heater generates a thermal wave which travels through the substrate and the gas until it reaches the pyroelectric material located across from the heater. When the pyroelectric material undergoes a temperature change, it produces a measurable electrical current, which has a corresponding voltage [57]. The voltage can be used to find the composition of the gas, as it is dependent on the thermal conductivity and diffusivity of the gas [58]. Another type of pyroelectric sensor involves using an intense infrared light source on a pyroelectric thin film to generate heat, as shown in Figure 3. Once the pyroelectric material changes temperature, the sensor operates similarly to the electric heater method [58].

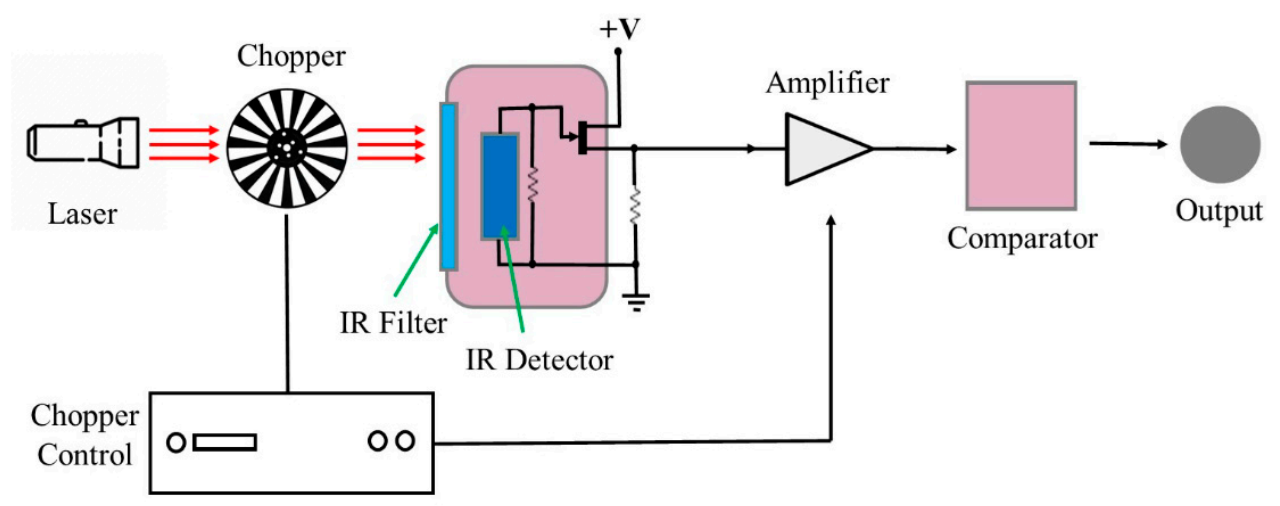

Figure 3. Schematic of pyroelectric sensor based on infrared heating.

Some advantages of the pyroelectric methane sensor include its ability to operate without oxygen, good sensitivity and responsivity, and wide measuring range [53]. It can also perform well at room 
temperature without the need for constant cooling, which reduces operational costs [54]. In addition, the pyroelectric effect is a thermal process which does not involve any chemical reactions, so the risk of degradation is reduced. However, pyroelectric sensors are expensive and require high power supply and large equipment to accommodate the need for a constant heat or infrared source, which makes them immobile and unfit for many applications [54]. In addition, they are difficult to manufacture, since a thin pyroelectric element has to be secured onto a supporting base [59-63]. Even though some pyroelectric methane sensors are currently on the market, the sensor design can be researched further to improve the overall sensitivity and reduce power consumption.

\section{Recent Research Developments}

Tan et al. [58] fabricated a pyroelectric infrared sensor with a lead zirconate titanate (PZT) thin film as the infrared sensing film. The PZT film was prepared by a sol-gel process, which used lead acetate trihydrate, zirconium acetylacetone, acetylacetone, and titanium isopropoxide as starting materials. An infrared structure on silicon substrate with a micro bridge was designed for methane detection. Experimental results showed successful methane detection based on the infrared sensor element. Querner et al. [64] presented and analyzed a novel procedure for increasing the sensitivity of a pyroelectric sensor. The tested sensor had single-crystalline lithium tantalate as its thin film pyroelectric material. The responsivity was improved using lateral heat flux spreading, due to a 3-dimensional pattern that was etched into the sensitive element. The thin regions between thicker regions showed faster heating due to incident radiation, which led to an additional heat flow from the intermediate regions to the sensitive element. Dong et al. [65] developed a multi-gas sensor system that utilizes a single broadband light source and multiple carbon monoxide, carbon dioxide and methane pyroelectric sensors using the time division multiplexing (TDM) technique. A stepper motor-based rotating system and a single-reflection spherical optical mirror were designed and integrated to enhance multi-gas detection. It was experimentally determined that the $1 \sigma$ detection limit under static operation was $2.84 \mathrm{ppm}-\mathrm{v}$ for methane, and under dynamic operation, it was $10.29 \mathrm{ppm}-\mathrm{v}$. Liu et al. [66] implemented a portable methane detection device based on direct absorption spectroscopy. The device included a dual-channel non-dispersive infrared pyroelectric sensor, a driving circuit of the sensor, an ARM11 embedded WinCE system, and a LabVIEW-based data-processing platform. The experimental results showed that the $1 \sigma$ detection limit of the device is $4.8 \mathrm{ppm}-\mathrm{v}$ with an average time of $1 \mathrm{~s}$ on the gas sample with concentration of 0 . Experiments were also conducted on three methane samples with different concentrations to test the response time, which was found to be less than $20 \mathrm{~s}$. Hu et al. [67] designed and tested a methane sensor system based on a novel quartz-tuning-fork (QTF)-embedded, double-pass, off-beam quartz-enhanced photoacoustic spectroscopy (DP-OB-QEPAS). A simplified numerical model was used to optimize the DP-OB-QEPAS spectrophone and enhance the detection sensitivity. A continuous-wave distributed feedback diode laser for methane detection was also employed. The sensor was calibrated for methane trace detection and a $1 \sigma$ detection limit of $8.62 \mathrm{ppm}-\mathrm{v}$ for an average time of $0.3 \mathrm{~s}$ was achieved. Dorojkine [57] developed a thermal wave pyroelectric film methane and natural gas sensor by using $\mathrm{Al}_{2} \mathrm{O}_{3} / \mathrm{SiO}_{2}$ as a substrate which has a high thermal conductivity. He found that the sensor detection limit was $0.1 \%$ for methane gas and the response time was $40-60 \mathrm{~s}$.

\section{Semiconducting Metal Oxide Sensors}

Semiconducting metal oxide (SMO) sensors are electrical conductivity sensors that detect species based on the oxidation and reduction reactions that happen between the SMO and target gases. The gas of interest absorbs onto the active sensing layer, causing a change in the electrical resistance, from which the concentration of the gas can be determined [68]. SMO sensors are used for many applications including safety equipment (explosion, leakage, fire, contamination, poisoning protection) and air quality monitoring. There are two main types of SMO, n-type and p-type. The electron is the major carrier in the n-type SMO (tin dioxide, iron (III) oxide), while the hole is the major carrier in the 
p-type SMO (nickel oxide m, cobalt oxide) [69]. SMO methane sensors are mostly n-type because the electrons are produced by oxygen vacancies naturally [70,71]. An n-type SMO sensor possesses some electrical resistance from tiny crystals of n-type metal oxide semiconductors, such as $\mathrm{SnO}_{2}$ or $\mathrm{WO}_{3}$ [72]. When exposed to an atmosphere containing a reducing gas like methane, the SMO surface absorbs the gas molecules which lowers the potential barrier, thus increasing the concentration of electrons at the surface while reducing the electrical resistance [73]. It has been reported that the conductivity response is highly affected by the presence of a catalyst, which would increase the surface reactivity [74]. Figure 4 shows the gas sensing mechanism of a SMO sensor design.

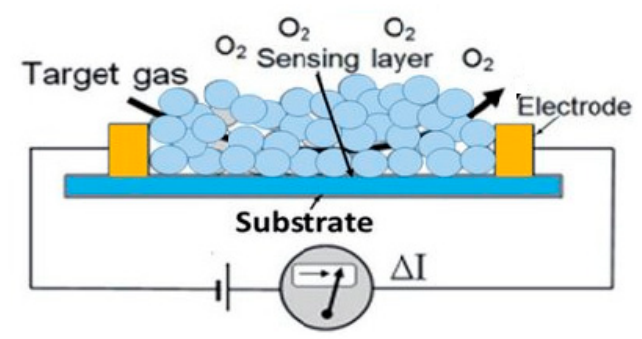

Figure 4. Gas sensing mechanism of metal oxides. Adapted from [75].

SMO sensors are used for a wide range of applications because they are inexpensive compared to other sensing technologies, lightweight and robust [76]. In addition, SMO sensors have long lifespans and are resistant to poisoning [73]. However, there are some drawbacks for SMO sensors, including poor selectivity, small and high operational temperature range, slow recovery rate, and significant additive dependency. In addition, the sensor sensitivity can be affected by the temperature, susceptible to degradation, and sensitive to changes in humidity $[19,71]$.

\section{Recent Research Developments}

The sensitivity and rate of response of SMO sensors can be improved by modifying the materials of the components, such as doping the metal oxide layer. Xue et al. [77] developed an enhanced resistance-based methane sensor based on platinum-doped tin (IV) oxide $\left(\mathrm{SnO}_{2}\right)$ nanoflowers. Pt-doped $\mathrm{SnO}_{2}$ was synthesized by a hydrothermal process, followed by a simple thermal reduction method. It was found that the nanoflowers improved the sensitivity and lowered the optimal operating temperature by reducing the surface adsorption energy of the material which led to more methane gas molecules being adsorbed. The improvement in the sensor performance was mainly attributed to the chemical sensitization of $\mathrm{Pt}$ dopant to methane gas. Ghanbari et al. [78] investigated the methane sensing properties of graphene (G), decorated with silver nanoparticles (AgNPs). Experiments were conducted at relatively low temperatures and different levels of humidity, for various silver-to-graphene mass ratios and methane concentrations. The results showed that for methane concentrations lower than 2000 ppm-m, the response increases linearly and rapidly, even at room temperature. It was also demonstrated that the sensor based on $\mathrm{AgNPs} / \mathrm{G}$ had a low limit of detection, and was highly stable, selective, reversible and repeatable, thus showing promise as a cost-effective and simple-to-fabricate methane sensing device. Oleksenko et al. [79-81] presented a series of studies on semiconductor methane sensors based on $\mathrm{SnO}_{2}$ nanomaterials. In [79], nanosized palladium-containing $\mathrm{SnO}_{2}$ was obtained by a sol-gel technique, and its influence on the sensor sensitivity to methane was studied. The results indicated that $\mathrm{Pd} / \mathrm{SnO}_{2}$ significantly increased (by approximately -7 times) the sensor response in comparison to non-doped materials, with a fast response and recovery time as well. In [80], the authors studied the catalytic activities and the sensitivities of adsorption of $\mathrm{Pd} / \mathrm{SnO}_{2}$ nanomaterials with various Pd contents in the oxidation of methane. It was found that response of the sensors to methane was determined by the catalytic activities of the gas-sensitive layers in the oxidation of methane by oxygen chemisorbed onto active sites localized at the $\mathrm{Pd} / \mathrm{SnO}_{2}$ interface. In [81], a platinum-containing adsorption-semiconductor sensor based on nanosized $\mathrm{SnO}_{2}$ was developed 
and found to have higher sensitivity to methane than other common $\mathrm{SnO}_{2}$-based sensors. It was experimentally determined that the sensitivity of the sensor to methane depended on the Pt content of the gas-sensitive layer, which can be explained by the influence of the catalytic oxidation of methane that occurs on the surface of the sensor. Moalaghi et al. [82] developed a dopant-free $\mathrm{SnO}_{2} \mathrm{methane}$ sensor, heated using a 10 micron-thick microheater which can operate at temperatures as high as $850{ }^{\circ} \mathrm{C}$, sufficient for the spontaneous pyrolysis of methane. The sensor was able to selectively sense methane in atmospheres contaminated with $\mathrm{CO}$ and $\mathrm{H}_{2}$, with both the response and recovery time being approximately $10 \mathrm{~s}$ and the methane detection limit being $50 \mathrm{ppm}-\mathrm{m}$. Shaalan et al. [83] investigated the morphology and gas sensing characteristics of $\mathrm{Co}_{3} \mathrm{O}_{4}$ nanoparticles prepared using microwave irradiation. The methane sensor based on synthesis $\mathrm{Co}_{3} \mathrm{O}_{4}$ nanoparticles was found to have faster response and recovery time at low temperatures. For a methane concentration of $1 \%$, the response and the recovery time at $200{ }^{\circ} \mathrm{C}$ were $100 \mathrm{~s}$ and $50 \mathrm{~s}$, respectively. The results also showed that the sensing characteristics of $\mathrm{Co}_{3} \mathrm{O}_{4}$ nanoparticles were improved by increasing the temperatures and methane concentrations, demonstrating its potential use as a sensing material for SMO methane sensors.

\section{Electrochemical Sensors}

Electrochemical sensors are chemical sensors where the receptor and the transducer are coupled, as defined by the International Union of Pure and Applied Chemistry (IUPAC) [84]. Electrochemical sensors are mostly sensitive, selective, inexpensive, and can be used widely for environmental monitoring such as leak detection, emission monitoring, and fire safety [85,86]. The sensor design consists of a working electrode where methane undergoes an oxidation reaction, a counter electrode which balances the current at the working electrode, and a reference electrode with which to measure the working electrode potential. The working and counter electrodes are connected by an electrolytic fluid to maintain charge neutrality in the system. The schematic of an electrochemical sensor is shown in Figure 5. The measured current between the working and counter electrodes is proportional to the concentration of methane detected. The selection of materials for the electrolyte, electrodes and catalyst defines the properties of electrochemical sensors and their applications [87]. The classification of electrochemical sensors according to the applied electrochemical transduction mode include potentiometric sensors, voltammetric/amperometric sensors, and conductometric sensors [84,88-90]. Potentiometric sensors measure the electrical potential of an electrode when no current is present. Amperometric sensors detect the gas concentration as a function of the current at a fixed potential, while in voltammetric sensors, the current is determined as a function of the potential that varies continuously or stepwise [84,91]. Conductometric sensors operate based on the changes in the electrical conductivity of a material or a film due to the presence of a target gas [92].

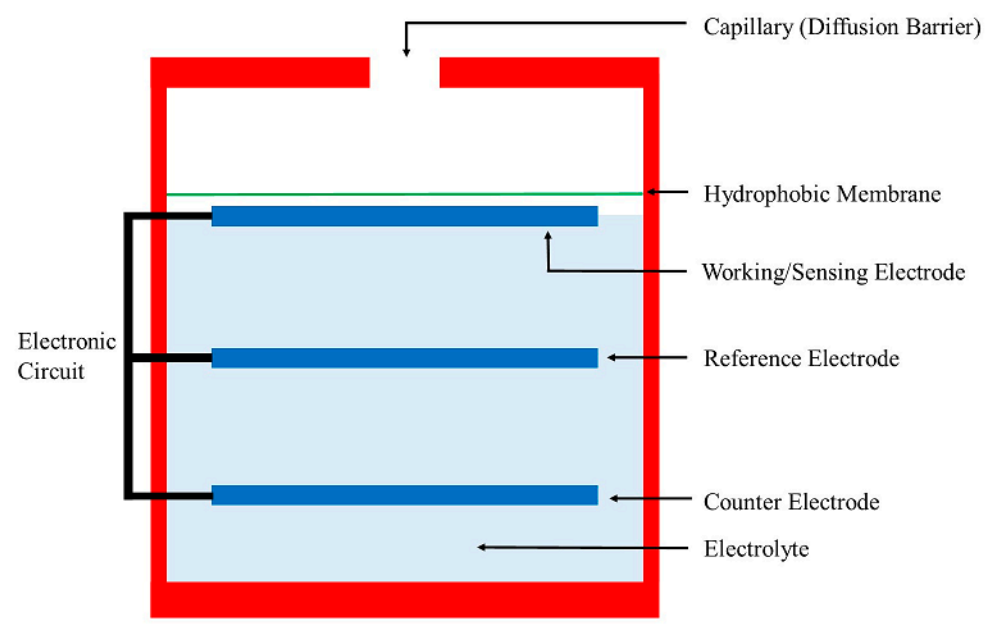

Figure 5. Schematic of an electrochemical sensor. 
There are two main types of electrolytes for electrochemical methane sensors, which are liquid electrolytes (aqueous electrolytes and ionic liquid electrolytes) and solid electrolytes. Aqueous electrolytes (AEs) are inexpensive, widely available, and simple to use. Some examples of common AEs are sulfuric acid $\left(\mathrm{H}_{2} \mathrm{SO}_{4}\right)$ and sodium hypochlorite $(\mathrm{NaClO})$. In 1963, an electrochemical cell consisting of platinum electrodes and aqueous phosphoric acid and sulfuric acid electrolyte was capable of oxidizing methane in the $60-150{ }^{\circ} \mathrm{C}$ range, paving the way for future methane detecting applications using AEs $[93,94]$. However, the volatility properties and wide potential window of the AEs are the major problems that limit the use of AE-based sensors [95]. Evaporation of the AE requires frequent refilling which increases the cost of the sensor [96]. The partial oxidation reaction of methane could occur, causing catalyst poisoning and shortening the lifespan of the sensor [97]. In addition, the liquid electrolytes cause problems when they are used in gas sensors because they fill the pores and slow down gas diffusion to the electrode, which results in low sensitivity and slow response time. For these reasons, research and development works have focused on solid-state electrolytes or ionic liquids.

Ionic liquids (ILs) have recently gained traction for use in gas sensor design because their unique properties bridge the gaps left by AEs, allowing new design pathways and functionalities. In particular, room-temperature ILs (RTILs), which are liquid salts at room temperature, have found increasingly common use in modern gas sensor designs since they circumvent the extreme conditions required for certain oxidation pathways of methane analyte [97,98]. Some important properties of RTILs include negligible vapor pressure, high thermal stability, higher density than water, good electrochemical window, high ionic conductivity, high polarity, and unique structure and interaction of ions [99]. RTILs are ideal for electrochemical methane sensors because they have higher boiling points and more negligible volatility than their AE counterparts, and thus do not dry out during use [100]. RTILs are also less hazardous than the common acid electrolytes used in AE systems, making them great candidates for wide industrial production and use. The manufacturing of RTIL electrochemical sensors, however, still faces some problems, such as potential liquid leakage from the sensor and slow gas diffusion caused by liquid filling the pores [101].

Solid electrolytes (SEs), as a replacement of liquid electrolytes, improve the safety and flexibility of gas sensing applications. The main principle applied in SE sensors is the establishment of electrochemical equilibrium at the electrodes, which results in a quantifiable equilibrium voltage, according to the Nernst equation [102]. Moreover, through oxygen anions being transported through the solid electrolyte, methane oxidation can occur. Metal oxides [102], inorganic salts [47], and doped polymers $[47,103]$ can be used as solid electrolytes, as they show significant ionic conductivities over a sufficiently wide temperature range. In some older works, a sodium phosphate solid electrolyte with a hydrogenation catalyst was developed to detect methane gas at $600{ }^{\circ} \mathrm{C}$ [104]. In addition, yttria-stabilized zirconia solid electrolyte tubes with silver electrodes were used to detect methane at $735^{\circ} \mathrm{C}$ and $0.1 \mathrm{MPa}$ [105]. Most SE sensors can only work at high temperatures for the oxidation reaction to occur, which limits the wide use of this type of sensor. They are also unable to detect low concentrations of gas and are susceptible to the degradation or loss of electrolyte.

\section{Recent Research Developments}

More recent research on electrochemical methane sensors has focused on ILs, rather than AEs. Wang et al. [106] investigated the oxidation of methane, with three different electrodes (platinum, gold, and carbon) and six different ILs, by cyclic voltammetry. For a Pt electrode and bis(trifluoromethylsulfonyl)imide ( $\mathrm{NTf}_{2}$ )-based ILs, a unique catalytic Pt-NTf ${ }_{2}$ interface for electron transfer reaction of methane was reported, while little methane electro-oxidation signal was observed in ILs with other anions. The final methane oxidation products were determined to be $\mathrm{CO}_{2}$ and water by in-situ infrared spectroelectrochemistry, which was further confirmed by the characteristic of peak potential shifts of the oxygen redox processes. The results led to the proposal of a mechanism suggesting a potential catalytic system of methane oxidation in $\mathrm{NTf}_{2}$-based ILs that strongly depends on the properties of the ILs and the electrode materials. The same authors then developed an electrochemical 
methane sensor using a non-volatile and conductive pyrrolidinium-based IL electrolyte and a novel internal method for methane and oxygen dual-gas detection with high sensitivity, selectivity, and stability [97]. Using the previous findings that methane is electro-oxidized to produce $\mathrm{CO}_{2}$ and water at a Pt electrode and $\mathrm{NTf}_{2}$-based ILs, the authors quantify the electrochemical sensor signal using the $\mathrm{CO}_{2}$ generated from methane oxidation. The IL-based methane sensor was validated using both conventional solid macroelectrodes and flexible microfabricated electrodes with single- and double-potential step chronoamperometry. Yin et al. [107] presented a robust microfabricated planar electrochemical gas sensor with RTIL $\left(\left[\mathrm{C}_{4} \mathrm{mpy}\right]\left[\mathrm{NTf}_{2}\right]\right)$ as the electrolyte. Experimental methane sensing was conducted with good results, $0.3 \mu \mathrm{A} / \mathrm{cm}^{2}$ sensitivity and $0.9991 \mathrm{R} 2$ linearity value in the range of $0-6 \%$ methane. In [108], the same group of authors further developed the previous sensor by using a porous polytetrafluoroethylene substrate that enables fast gas diffusion. Metal sputtering was utilized for Pt electrodes fabrication to increase adhesion between the electrodes and the substrate. The microsensor was found to provide better sensitivity, linearity, and repeatability for oxygen and methane monitoring.

Aside from ILs, SEs have also been researched for use in electrochemical methane sensors. Sekhar et al. [109] developed a mixed potential-based sensor using tin-doped indium oxide (ITO), platinum electrodes and yttria-stabilized zirconia (YSZ) electrolyte. The sensor was fabricated using a cost-effective tape-cast method. Experimental results showed that the sensor response time was $15 \mathrm{~s}$, and that after $500 \mathrm{~h}$ of operation, a 5\% reduction in methane sensitivity was observed. A cross-sensitivity study performed on the sensor indicated minimal interference to $\mathrm{NO}, \mathrm{NO}_{2}$, and $\mathrm{CO}_{2}$. A signal conditioning method referred to as the pulsed discharge technique was implemented, which resulted in a four-fold increase in methane sensitivity. Gross et al. [110] presented the fabrication and testing of a voltammetric sensor, using Nafion solid-state electrolyte, that can operate in gaseous condition at room temperature. Nafion is a polymer that conducts protons $\left(\mathrm{H}^{+}\right)$generated from redox reactions from the working electrode to the counter electrode. It was shown that the sensor was capable of detecting methane, quantifying its concentration in the gas flow, and differentiating its signal from carbon monoxide. These results were validated by exposing the sensor to two different concentrations of methane ( $50 \%$ and $10 \%$ of methane diluted in $\mathrm{N}_{2}$ ), as well as pure CO. Dosi et al. [100] developed a room-temperature amperometric methane sensor, where porous laser-induced graphene (LIG) electrodes were integrated into polymer films with a palladium nanoparticle dispersion to distribute the electrocatalyst within the high surface area support. A pseudo-solid-state ionic liquid/polyvinylidene fluoride electrolyte was painted onto the cell creating a porous electrolyte to facilitate faster gas transport and enable the room-temperature electro-oxidation of methane. The performance of the sensor was evaluated for various methane concentrations and relative humidity levels, and tested against interfering gases. The sensor demonstrated the highest reported sensitivity $\left(0.55 \mu \mathrm{A} / \mathrm{ppm} / \mathrm{cm}^{2}\right)$ with a rapid response time (40 s) enabling sub-ppm detection. Yang et al. [111] fabricated a potentiometric methane sensor using $\mathrm{SmMn}_{2} \mathrm{O}_{5}$ as the sensing electrode and $\mathrm{YSZ}$ as the solid electrolyte. $\mathrm{SmMn}_{2} \mathrm{O}_{5}$ was prepared by the sol-gel method and characterized by X-ray diffraction, Brunauer-Emmett-Teller (BET) method, and scanning electron microscopy. As the operating temperature increased from 350 to $500{ }^{\circ} \mathrm{C}$, the methane sensitivity decreased while the response and recovery rates increased. The optimal temperature was determined to be $400{ }^{\circ} \mathrm{C}$, where the response and recovery time were significantly reduced to $27 \mathrm{~s}$ and $33 \mathrm{~s}$ for $400 \mathrm{ppm}-\mathrm{m}$ methane, respectively, and the sensitivity only decreased slightly. Overall, the sensor had a good methane selectivity with small cross sensitivity to $\mathrm{C}_{3} \mathrm{H}_{8}$ and $\mathrm{CO}_{2}$, and it also showed good reproducibility and long-term stability, indicating its potential for use in methane leakage warning.

\section{Comparison of Methane Sensors and Discussion of Future Challenges}

In summary, there has been some progress made to improve each of the discussed methane sensors, but they still have certain practical limitations. The working mechanisms, advantages and disadvantages of the sensors are summarized in Table 1. Researchers should take these points into 
consideration when working to enhance the respective type of sensor. For optical methane sensors, the advantages include immunity to electromagnetic interference, ability to operate without oxygen, and being a non-destructive method. Their disadvantages are high costs in large settings, and low selectivity due to the lack of distinctiveness of the methane optical absorption region. The advantages of calorimetric methane sensors include low cost, simple design, easy fabrication, and ability to operate in harsh conditions. However, they are susceptible to cracking, catalyst poisoning and accelerated degradation, and require high power consumption and elevated temperatures. Pyroelectric methane sensors can operate without oxygen, have good sensitivity, good responsivity and a wide measuring range, and perform well at room temperature. However, they are expensive and difficult to manufacture, and require high power consumption and large equipment which make them immobile. SMO methane sensors are generally inexpensive, lightweight, robust, long-lasting and resistant to poisoning. However, some drawbacks for SMO sensors include poor selectivity, a small and high operational temperature range, slow recovery rate, and significant dependence on additives, temperature and humidity. For electrochemical methane sensors, AE-based sensors suffer from leakage and evaporation, which can drive the cost up, as well as being hazardous compounds. IL-based sensors do not have the same problems, but they have low sensitivity and slow response time due to liquid filling the pores and slowing down gas diffusion to the electrode. SE-based sensors improve the safety and flexibility of gas sensing applications, but they work at high temperatures, are unable to detect low concentrations of gas, and can be affected by degradation or loss of electrolyte. Overall, the ideal methane sensor should have a low cost, high selectivity and sensitivity for methane, good fouling resistance, long lifespan, simple manufacturing process, and good detection range. Each of the discussed sensors has satisfied some of the requirements, with the potential to satisfy all, but more research needs to be conducted in order to create the ideal sensor for methane leak detection.

Table 1. Comparison of different methane sensors.

\begin{tabular}{|c|c|c|c|c|}
\hline Methane Sensor Types & Working Mechanisms & Advantages & Disadvantages & Related Research \\
\hline Optical sensors & $\begin{array}{l}\text { Detect changes in light } \\
\text { waves that result from an } \\
\text { interaction of the analyte } \\
\text { with the receptor part. }\end{array}$ & $\begin{array}{l}\text { Non-destructive method; Immune } \\
\text { to electromagnetic interference; } \\
\text { Operate without oxygen. }\end{array}$ & $\begin{array}{l}\text { High cost; High power consumption; Lack of } \\
\text { significance and distinctiveness of methane } \\
\text { optical absorption region. }\end{array}$ & {$[28,30-35]$} \\
\hline Calorimetric sensors & $\begin{array}{l}\text { Measure the heat } \\
\text { produced from a reaction } \\
\text { and correlate the value to } \\
\text { the reactant concentration. }\end{array}$ & $\begin{array}{l}\text { Low cost; Simplistic design; } \\
\text { Portable; Easy to manufacture; } \\
\text { Good selectivity for methane; Can } \\
\text { operate in harsh environmental } \\
\text { conditions. }\end{array}$ & $\begin{array}{l}\text { Low detection accuracy; Susceptible to } \\
\text { cracking, catalyst poisoning and } \\
\text { oversaturation; High power consumption; } \\
\text { Short lifespan; Require high temperature. }\end{array}$ & {$[40,48-52]$} \\
\hline Pyroelectric sensors & $\begin{array}{l}\text { Convert thermal energy } \\
\text { into electrical energy } \\
\text { based on the phenomenon } \\
\text { of pyroelectricity. }\end{array}$ & $\begin{array}{l}\text { Non-destructive; Operate without } \\
\text { oxygen; Good sensitivity and } \\
\text { responsivity; Wide measuring } \\
\text { range; Operate at room } \\
\text { temperature. }\end{array}$ & $\begin{array}{l}\text { High cost; High power consumption; } \\
\text { Immobile; Difficult to manufacture. }\end{array}$ & {$[57,58,64-67]$} \\
\hline $\begin{array}{l}\text { Semiconducting metal } \\
\text { oxide sensors }\end{array}$ & $\begin{array}{l}\text { Absorption of gas on the } \\
\text { surface of a metal oxide } \\
\text { changes its conductivity, } \\
\text { which is then quantified to } \\
\text { obtain the gas } \\
\text { concentration. }\end{array}$ & $\begin{array}{l}\text { Low cost; Lightweight and robust; } \\
\text { Long lifespan; Resistant to } \\
\text { poisoning. }\end{array}$ & $\begin{array}{l}\text { Poor selectivity; Small and high operational } \\
\text { temperature range; Slow recovery rate; } \\
\text { Significant additive dependency; Affected by } \\
\text { temperature; Susceptible to degradation; } \\
\text { Sensitive to changes in humidity }\end{array}$ & [77-83] \\
\hline Electrochemical sensors & $\begin{array}{l}\text { Measure the target gas } \\
\text { concentration by oxidizing } \\
\text { or reducing the gas at an } \\
\text { electrode and measuring } \\
\text { the resulting current. }\end{array}$ & $\begin{array}{l}\text { AE-based: Low cost. } \\
\text { IL-based: Non-hazardous } \\
\text { materials; High boiling points and } \\
\text { low volatility; Good selectivity for } \\
\text { methane; Can detect small leaks. } \\
\text { SE-based: No leakage; Safe; } \\
\text { Robust; Good selectivity for } \\
\text { methane; Can detect small leaks. }\end{array}$ & $\begin{array}{l}\text { AE-based: Susceptible to leakage and } \\
\text { evaporation; Hazardous materials; Slow } \\
\text { response time. } \\
\text { IL-based: Susceptible to leakage; Slow } \\
\text { response time. } \\
\text { SE-based: Require high temperature; Unable } \\
\text { to detect low gas concentrations; Susceptible } \\
\text { to degradation or loss of electrolyte. }\end{array}$ & {$[97,100,106-111]$} \\
\hline
\end{tabular}

There are several challenges affecting the performance of the sensor that need to be addressed including environmental factors like humidity, temperature, and wind, as well as gas impurities. The sensors can experience a wide range of weather conditions depending on the applications. Relative humidity can significantly affect the reliability and accuracy of methane detection. Using humidity filters or equipping the sensor with heating units or microheaters that increase the sensor surface can reduce the amount of moisture near and on the sensors [112]. Another solution to reduce the effect of humidity on the sensitivity of the sensors is to decrease or eliminate the dependence of the detection response on humidity by using new materials such as synthesis metal oxide with 
reduced sensitivity to moisture [113]. Temperature is another factor that affects the performance of the methane sensors [114]. Even though SMO methane sensors have a high selectivity, they are not widely used because of the high operational temperature that can cause explosion of the methane gas and damage the instruments. In addition, low temperatures can freeze the liquid electrolyte in the electrochemical sensor, and high temperatures can evaporate the liquid electrolyte or crack the solid electrolyte. Recently, gel electrolyte has been investigated because it is not highly dependent on temperature. Wind speed and direction can also affect the performance of the sensor, but it has not yet been examined thoroughly in literature. Finally, the performance of the methane sensors can be affected by impurities in the gas. There are several other gases such as $\mathrm{CO}_{2}, \mathrm{CO}, \mathrm{H}_{2} \mathrm{~S}, \mathrm{NO}_{\mathrm{x}}$ and $\mathrm{SO}_{\mathrm{x}}$ that may be present in the oil and gas pipelines and applications. These can affect the performance of electrochemical and SMO sensors where the impurities can poison the catalysts and optical sensors where a higher concentration of methane is needed for more selective and accurate detection. Overall, aside from the individual disadvantages of each methane sensor type, there are a few challenges they all face, and these challenges should be addressed in future research to improve the reliability of methane sensors and ultimately reduce methane emissions.

\section{Conclusions}

Methane is the primary component of natural gas. Due to potential defects in the natural gas pipeline network, methane leakage and fugitive emissions can occur, which leads to the largest man-made source of the hazardous greenhouse gas, and causes a significant loss in revenue for the industries. Therefore, methods and products to identify leaks quickly and reliably are very important for the methane distribution network. Methane sensors are seen as a cost-effective and efficient approach to the leakage of pipelines, distribution to services, other fugitive emissions problems. This paper introduced and discussed five prominent sensors used for methane detection, including optical sensors, calorimetric sensors, pyroelectric sensors, semiconducting metal oxide sensors, and electrochemical sensors. The comprehensive review included basic definitions, working mechanisms, advantages, and disadvantages of each sensor, as well as a summarized comparison between the sensors. Recent research developments and findings for each sensor was also discussed. This review paper on methane sensors serves as a basis for researchers to study and develop more accurate, reliable and practical sensors in the future to improve natural gas pipeline safety and reduce their environmental impact.

Author Contributions: Conceptualization, T.A., M.-K.T., M.P. and M.F.; formal analysis, T.A. and M.-K.T.; resources, T.A. and M.-K.T.; writing-original draft preparation, M.-K.T. and T.A.; writing—review and editing, R.V., M.P. and M.F.; visualization, M.-K.T. and R.V.; supervision, M.P. and M.F. All authors have read and agreed to the published version of the manuscript.

Funding: Canada Research Chair Tier I - Zero Emission Vehicles and Hydrogen Energy Systems Grant number: 950-232215, and The Natural Sciences and Engineering Research Council of Canada (NSERC), Discovery Grants Program, RGPIN-2020-04149.

Acknowledgments: This work was supported by the Department of Chemical Engineering at the University of Waterloo and the University of Hafr Al Batin though the Saudi Arabian Cultural Bureau in Canada. Special thanks to Danielle Skeba and Mitchell Lowery for their contribution in editing the paper.

Conflicts of Interest: The authors declare no conflicts of interest.

\section{References}

1. Global Methane Initiative. Global Methane Emissions and Mitigation Opportunities. 2011. Available online: www.globalmethane.org (accessed on 12 December 2019).

2. Turner, A.J.; Frankenberg, C.; Kort, E.A. Interpreting contemporary trends in atmospheric methane. Proc. Nat. Acad. Sci. USA 2019, 116, 2805-2813. [CrossRef] [PubMed]

3. Government of Canada. About Methane Emissions. 2014. Available online: https: //www.canada.ca/en/environment-climate-change/services/climate-change/global-methane-initiative/ about-methane-emissions.html (accessed on 23 November 2019). 
4. Stocker, T.F.; Dahe, Q.; Plattner, G.K.; Tignor, M.B.; Allen, S.K.; Boschung, J.; Nauels, A.; Xia, Y.; Bex, V.; Midgley, P. Climate Change 2013: The Physical Science Basis; Cambridge University Press: Cambridge, UK; New York, NY, USA, 2014.

5. Tran, M.-K.; Fowler, M. A Review of Lithium-Ion Battery Fault Diagnostic Algorithms: Current Progress and Future Challenges. Algorithms 2020, 13, 62. [CrossRef]

6. Jaramillo, P.; Griffin, W.M.; Matthews, H.S. Comparative analysis of the production costs and life-cycle GHG emissions of FT liquid fuels from coal and natural gas. Environ. Sci. Technol. 2008, 42, 59-65. [CrossRef] [PubMed]

7. Gagarin, H.; Sridhar, S.; Lange, I.; Bazilian, M. Considering non-power generation uses of coal in the United States. Renew. Sustain. Energy Rev. 2020, 124, 109790. [CrossRef]

8. Maroufmashat, A.; Fowler, M. Transition of future energy system infrastructure; through power-to-gas pathways. Energies 2017, 10, 1089. [CrossRef]

9. EIA. How Much Carbon Dioxide Is Produced When Different Fuels are Burned? 2018. Available online: https://www.eia.gov/tools/faqs/faq.php?id1/473\&t1/411 (accessed on 25 November 2019).

10. King, G.E.; King, D.E. Environmental risk arising from well-construction failure-Differences between barrier and well failure, and estimates of failure frequency across common well types, locations, and well Age. SPE Prod. Oper. 2013, 28, 323-344.

11. Bachu, S. Analysis of gas leakage occurrence along wells in Alberta, Canada, from a GHG perspective-Gas migration outside well casing. Int. J. Greenh. Gas Control 2017, 61, 146-154. [CrossRef]

12. Olmer, N.; Comer, B.; Roy, B.; Mao, X.; Rutherford, D. Greenhouse Gas Emissions from Global Shipping, 2013-2015. The International Council on Clean Transportation 2017. Available online: https://www.theicct. org/publications/GHG-emissions-globalshipping-2013-2015 (accessed on 25 November 2019).

13. Ingraffea, A.; Wawrzynek, P.A.; Santoro, R.; Wells, M.T. Reported methane emissions from active oil and gas wells in pennsylvania, 2014-2018. Environ. Sci. Technol. 2020, 54, 5783-5789. [CrossRef]

14. Wisen, J.; Chesnaux, R.; Werring, J.; Wendling, G.; Baudron, P.; Barbecot, F. A portrait of wellbore leakage in northeastern British Columbia, Canada. Proc. Natl. Acad. Sci. USA 2020, 117, 913-922. [CrossRef]

15. Government of Canada. Federal Regulations to Reduce Methane Emissions in the Oil and Gas Sector. Available online: https://www.canada.ca/en/environment-climate-change/news/2018/04/federalregulations-to-reduce-methane-emissions-in-the-oil-and-gas-sector.html\#targetText=Greenhouse \% 20gas\%20emission\%20reductions, the\%20road\%20for\%20a\%20year (accessed on 10 December 2019).

16. Lu, H.; Iseley, T.; Behbahani, S.; Fu, L. Leakage detection techniques for oil and gas pipelines: State-of-the-art. Tunn. Undergr. Space Technol. 2020, 98, 103249. [CrossRef]

17. Dey, A. Semiconductor metal oxide gas sensors: A review. Mater. Sci. Eng. 2018, 229, 206-217. [CrossRef]

18. Wu, Y.; Yao, B.; Yu, C.; Rao, Y. Optical graphene gas sensors based on microfibers: A review. Sensors 2018, 18, 941. [CrossRef] [PubMed]

19. Korotcenkov, G. Handbook of Gas Sensor Materials: Properties, Advantages and Shortcomings for Applications Volume 1: Conventional Approaches; Springer New York; Springer e-books; Imprint; Springer: New York, NY, USA, 2013.

20. Jaaniso, R.; Tan, O.K. Semiconductor Gas Sensors; Woodhead Pub: Cambridge, UK, 2013.

21. Spain, E.; Venkatanarayanan, A. Review of physical principles of sensing and types of sensing materials. In Sensor Materials, Technologies and Applications; ScienceDirect: Dublin, Ireland, 2014; pp. 5-46.

22. Triki, M.; Nguyen, B.T.; Vicet, A. Compact sensor for methane detection in the mid infrared region based on quartz enhanced photoacoustic spectroscopy. Infrared Phys. Technol. 2015, 69, 74-80. [CrossRef]

23. Butt, M.A.; Degtyarev, S.A.; Khonina, S.N.; Kazanskiy, N.L. An evanescent field absorption gas sensor at mid-IR $3.39 \mu \mathrm{m}$ wavelength. J. Mod. Opt. 2017, 64, 1892-1897. [CrossRef]

24. Massie, C.; Stewart, G.; McGregor, G.; Gilchrist, J.R. Design of a portable optical sensor for methane gas detection. Sens. Actuators B Chem. 2016, 113, 830-836. [CrossRef]

25. Gershon, J.S.; Ballinger, J.T. Spectroscopy. In Chemical Technicians' Ready Reference Handbook, 5th ed.; McGraw-Hill: New York, NY, USA, 2011.

26. Wolfbeis, O.S. Fiber-optic chemical sensors and biosensors. Anal. Chem. 2002, 74, 2663-2678. [CrossRef] [PubMed]

27. Shemshad, J.; Aminossadati, S.M.; Kizil, M.S. A review of developments in near infrared methane detection based on tunable diode laser. Sens. Actuators B Chem. 2012, 171, 77-92. [CrossRef] 
28. Yang, J.; Zhou, L.; Huang, J.; Tao, C.; Li, X.; Chen, W. Sensitivity enhancing of transition mode long-period fiber grating as methane sensor using high refractive index polycarbonate/cryptophane A overlay deposition. Sens. Actuators B Chem. 2015, 207, 477-480. [CrossRef]

29. Ryoko, Y.; Masaki, K.; Koji, F.; Tadashi, S.; Yoshihisa, S. Highly sensitive laser based trace-gas sensor technology and its application to stable isotope ratio analysis. NTT Tech. Rev. 2014, 12, 4.

30. Zheng, C.; Ye, W.; Sanchez, N.P.; Li, C.; Dong, L.; Wang, Y.; Griffin, R.J.; Tittel, F.K. Development and field deployment of a mid-infrared methane sensor without pressure control using interband cascade laser absorption spectroscopy. Sens. Actuators B Chem. 2017, 244, 365-372. [CrossRef]

31. Dong, L.; Yin, W.; Ma, W.; Zhang, L.; Jia, S. High-sensitivity, large dynamic range, auto-calibration methane optical sensor using a short confocal Fabry-Perot cavity. Sens. Actuators B Chem. 2007, 127, 350-357. [CrossRef]

32. Zhang, J.Y.; Ding, E.J.; Xu, S.C.; Wang, X.X.; Song, F. Sensitization of an Optical Fiber Methane Sensor with graphene. Opt. Fiber Technol. 2017, 37, 26-29. [CrossRef]

33. Tombez, L.; Zhang, E.J.; Orcutt, J.S.; Kamlapurkar, S.; Green, W.M.J. Methane absorption spectroscopy on a silicon photonic chip. Optica 2017, 4, 1322. [CrossRef]

34. Campanella, C.E.; de Carlo, M.; Cuccovillo, A.; de Leonardis, F.; Passaro, V.M.N. Methane gas photonic sensor based on resonant coupled cavities. Sensors 2019, 19, 5171. [CrossRef] [PubMed]

35. Ismaeel, R.; Beaton, A.; Donko, A.; Talataisong, W.; Lee, T.; Brotin, T.; Brambilla, G. high sensitivity all-fibre methane sensor with gas permeable Teflon/Cryptophane-A membrane. In Proceedings of the 2019 Conference on Lasers and Electro-Optics Europe \& European Quantum Electronics Conference (CLEO/Europe-EQEC), Munich, Germany, 23-27 June 2019; p. 1.

36. Huang, X.; Sheng, P.; Tu, Z.; Zhang, F.; Wang, J.; Geng, H.; Zou, Y.; Di, C.; Yi, Y.; Sun, Y.; et al. A two-dimensional $\pi-d$ conjugated coordination polymer with extremely high electrical conductivity and ambipolar transport behaviour. Nat. Commun. 2015, 6, 1-8. [CrossRef]

37. Xie, S.; Pennetta, R.; Russell, P.S.J. Self-alignment of glass fiber nanospike by optomechanical back-action in hollow-core photonic crystal fiber. Optica 2016, 3, 277-282. [CrossRef]

38. Kohl, C.D.; Wagner, T. Gas Sensing Fundamentals; Springer: Berlin/Heidelberg, Germany, 2014; Volume 15.

39. Chou, J. Hazardous Gas Monitors: A Practical Guide to Selection, Operation and Applications; McGraw-Hill: New York, NY, USA, 2001.

40. Park, N.H.; Akamatsu, T.; Itoh, T.; Izu, N.; Shin, W. Calorimetric thermoelectric gas sensor for the detection of hydrogen, methane and mixed gases. Sensors 2014, 14, 8350-8362. [CrossRef]

41. Dücso, C.; Ádám, M.; Fürjes, P.; Hirschfelder, M.; Kulinyi, S.; Bársony, I. Explosion-proof monitoring of hydrocarbons by mechanically stabilised, integrable calorimetric microsensors. Sens. Actuators B Chem. 2003, 95, 189-194.

42. Yamauchi, S. Chemical Sensor Technology; Kodansha; Elsevier Science: Amsterdam, The Netherlands, 1992.

43. Schierbaum, K.D.; Weimar, U.; Göpel, W.; Kowalkowski, R. Conductance, work function and catalytic activity of SnO2-based gas sensors. Sens. Actuators B Chem. 1991, 3, 205-214. [CrossRef]

44. Ho, C.K.; Itamura, M.T.; Kelley, M.J.; Hughes, R.C. Review of chemical sensors for in-situ monitoring of volatile contaminants. Sandia Rep. 2001, 28. [CrossRef]

45. Sberveglieri, G. Gas Sensors: Principles, Operation and Developments; Springer International Publishing: Cham, Switzerland, 1992.

46. Liu, X.; Cheng, S.; Liu, H.; Hu, S.; Zhang, D.; Ning, H. A survey on gas sensing technology. Sensors 2012, 12, 9635-9665. [CrossRef] [PubMed]

47. Azad, A.M.; Akbar, S.A.; Mhaisalkar, S.G.; Birkefeld, L.D.; Goto, K.S. Solid-state gas sensors-A review. J. Electrochem. Soc. 1992, 139, 3690-3704. [CrossRef]

48. Krebs, P.; Grisel, A. A low-power integrated catalytic gas sensor. Sens. Actuators B Chem. 1993, 13, $155-158$. [CrossRef]

49. Bíró, F.; Dücső, C.; Radnóczi, G.Z.; Baji, Z.; Takács, M.; Bársony, I. ALD nano-catalyst for micro-calorimetric detection of hydrocarbons. Sens. Actuators B Chem. 2017, 247, 617-625. [CrossRef]

50. Alpert, B.; Ferri, E.; Bennett, D. Algorithms for identification of nearly-coincident events in calorimetric sensors. J. Low Temp. Phys. 2016, 184, 263-273. [CrossRef]

51. Gardner, E.L.; Luca, A.D.; Falco, C.; Udrea, F. Geometrical optimisation of diode-based calorimetric thermal flow sensors through multiphysics finite element modelling. Proceedings 2017, 1, 280. [CrossRef] 
52. Shen, G.; Zheng, X.; Zhang, Y.; Wang, R. The Designed MEMS Methane Sensor Based on Pulse Power Supply. IOP Conf. Ser.: Earth Environ. Sci. 2019, 300, 42029. [CrossRef]

53. Fraden, J. Handbook of Modern Sensors: Physics, Designs, and Applications, 5th ed.; Springer International Publishing: Cham, Switzerland, 2016.

54. Jun, L.; Qiulin, T.; Wendong, Z.; Chenyang, X.; Tao, G.; Jijun, X. Miniature low-power IR monitor for methane detection. Measurement 2011, 44, 823-831. [CrossRef]

55. Alexander, B. Mathematical Processing of a Pyroelectric Detector; Ivanchenko: Volodymyr Dahl, East Ukrainian, 2019.

56. Yukinori, Y.; Toshiaki, S.; Kenichi. The pyroelectric sensor. Jpn. J. Appl. Phys. 1981, 20, 221-224.

57. Dorojkine, L.M. The non-catalytic thermal wave-based chemical gas sensor for methane and natural gas. Sens. Actuators B Chem. 2003, 89, 76-85. [CrossRef]

58. Qiu-lin, T.; Wen-dong, Z.; Chen-yang, X.; Ji-jun, X.; Jun, L.; Jun-hong, L.; Ting, L. Design, fabrication and characterization of pyroelectric thin film and its application for infrared gas sensors. Microelectron. J. 2009, 40, 58-62. [CrossRef]

59. Shikha, S.; Zheng, X.; Zhang, Y. Upconversion nanoparticles-encoded hydrogel microbeads-based multiplexed protein detection. Nano-Micro Lett. 2018, 10, 31. [CrossRef]

60. Song, M.K.; Rhee, H.W. Ultraviolet-cured polyethylene glycol diacrylate/polyvinylidene fluoride blend gel polymer electrolytes. Electrochem. Solid-State Lett. 2001, 4, A105. [CrossRef]

61. Acton, Q.A. Ethylene Glycols-Advances in Research and Application; Scholarly Editions: Atlanta, GA, USA, 2013.

62. Song, M.K.; Kim, Y.T.; Kim, Y.T.; Cho, B.W.; Popov, B.N.; Rhee, H.W. Thermally stable gel polymer electrolytes. J. Electrochem. Soc. 2003, 150, A439. [CrossRef]

63. Wamer, J.H.; Schaffel, F.; Rummeli, M.; Bachmatiuk, A. Graphene: Fundamentals and Emergent Applications; Elsevier: Kidlington, Oxford, UK, 2012.

64. Querner, Y.; Norkus, V.; Gerlach, G. High-sensitive pyroelectric detectors with internal thermal amplification. Sens. Actuators B Chem. 2011, 172, 169-174. [CrossRef]

65. Dong, M.; Zheng, C.; Miao, S.; Zhang, Y.; Du, Q.; Wang, Y.; Tittel, F. Development and measurements of a mid-infrared multi-gas sensor system for $\mathrm{CO}, \mathrm{CO}_{2}$ and $\mathrm{CH}_{4}$ Detection. Sensors 2017, 17, 2221. [CrossRef]

66. Liu, H.; He, Q.; Zheng, C.; Wang, Y. Development of a portable mid-infrared methane detection device. Optoelectron. Lett. 2017, 13, 100-103. [CrossRef]

67. Hu, L.; Zheng, C.; Zhang, M.; Yao, D.; Zheng, J.; Zhang, Y.; Wang, Y.; Tittel, F.K. Quartz-enhanced photoacoustic spectroscopic methane sensor system using a quartz tuning fork-embedded, double-pass and off-beam configuration. Photoacoustics 2020, 18, 100174. [CrossRef]

68. Seiyama, T.; Kato, A.; Fujiishi, K.; Nagatani, M. A New detector for gaseous components using semiconductive thin films. Anal. Chem. 1962, 34, 1502-1503. [CrossRef]

69. Prabakaran, S.; John, B.; Balaguru, R. Gas sensing mechanism of metal oxides: The role of ambient atmosphere, type of semiconductor and gases. A review. Sci. Lett. J. 2015, 4, 1262015.

70. Zhang, J.; Qin, Z.; Zeng, D.; Xie, C. Metal-oxide-semiconductor based gas sensors: Screening, preparation, and integration. Phys. Chem. Chem. Phys. 2017, 19, 6313-6329. [CrossRef] [PubMed]

71. Li, Z.; Li, H.; Wu, Z.; Wang, M.; Luo, J.; Torun, H.; Hu, P.; Yang, C.; Grundmann, M.; Liu, X.; et al. Advances in designs and mechanisms of semiconducting metal oxide nanostructures for high-precision gas sensors operated at room temperature. Mater. Horiz. 2019, 6, 470-506. [CrossRef]

72. Rajaković, L.; Milosavljević, D. Possibilities of application of piezoelectric sensors for the detection of explosives based on nitroaromatic compounds. Vojnoteh. Glas. 1996, 44, 570-576. [CrossRef]

73. Kanan, M.S.; El-Kadri, M.O.; Abu-Yousef, A.I.; Kanan, C.M. Semiconducting metal oxide based sensors for selective gas pollutant detection. Sensors 2009, 9, 8158-8196. [CrossRef]

74. Wetchakun, K.; Samerjai, T.; Tamaekong, N.; Liewhiran, C.; Siriwong, C.; Kruefu, V.; Wisitsoraat, A.; Tuantranont, A.; Phanichphant, S. Semiconducting metal oxides as sensors for environmentally hazardous gases. Sens. Actuators B Chem. 2011, 160, 580-591. [CrossRef]

75. Basu, S. Multilayer Thin Films: Versatile Applications for Materials Engineering; IntechOpen: London, UK, 2020.

76. Fine, G.F.; Cavanagh, L.M.; Afonja, A.; Binions, R. Metal oxide semi-conductor gas sensors in environmental monitoring. Sensors 2010, 10, 5469-5502. [CrossRef] 
77. Xue, D.; Wang, P.; Zhang, Z.; Wang, Y. Enhanced methane sensing property of flower-like $\mathrm{SnO}_{2}$ doped by $\mathrm{Pt}$ nanoparticles: A combined experimental and first-principle study. Sens. Actuators B Chem. 2019, 296, 126710. [CrossRef]

78. Ghanbari, R.; Safaiee, R.; Sheikhi, M.H.; Golshan, M.M.; Horastani, Z.K. Graphene decorated with silver nanoparticles as a low-temperature methane gas sensor. ACS Appl. Mater. Interfaces 2019, 11, 21795-21806. [CrossRef]

79. Fedorenko, G.; Oleksenko, L.; Maksymovych, N.; Skolyar, G.; Ripko, O. Semiconductor gas sensors based on $\mathrm{Pd} / \mathrm{SnO}_{2}$ nanomaterials for methane detection in air. Nanoscale Res. Lett. 2017, 12, 329. [CrossRef]

80. Oleksenko, L.P.; Fedorenko, G.V.; Maksymovych, N.P. Highly sensitive to methane sensor materials based on Nano-Pd/SnO 2 . Theor. Exp. Chem. 2019, 55, 1-5. [CrossRef]

81. Oleksenko, L.P.; Fedorenko, G.V.; Maksymovych, N.P. Platinum-containing adsorption-semiconductor sensors based on nanosized tin dioxide for methane detection. Theor. Exp. Chem. 2017, 53, 259-264. [CrossRef]

82. Moalaghi, M.; Gharesi, M.; Ranjkesh, A.; Hossein-Babaei, F. Tin oxide gas sensor on tin oxide microheater for high-temperature methane sensing. Mater. Lett. 2019, 263, 127196. [CrossRef]

83. Shaalan, N.M.; Rashad, M.; Moharram, A.H.; Abdel-Rahim, M.A. Promising methane gas sensor synthesized by microwave-assisted Co3O4 nanoparticles. Mater. Sci. Semicond. Process. 2016, 46, 1-5. [CrossRef]

84. Stoytcheva, M.; Zlatev, R. Electrochemical sensors for environmental analysis. In Encyclopedia of Applied Electrochemistry; Springer: New York, NY, USA, 2014; pp. 1-515.

85. Coillier, A. Gas Detection-An Introduction to Electrochemical Sensor Technology 2015. Available online: https://www.azosensors.com/article.aspx?ArticleID=618 (accessed on 21 December 2019).

86. Tsiplakides, D. Electrochemical sensor of gaseous contaminants. In Encyclopedia of Applied Electrochemistry; Springer: New York, NY, USA, 2014; pp. 379-893.

87. Mari, C.M.; Barbi, G.B. Electrochemical Gas Sensors. In Gas Sensors: Principles, Operation and Developments; Springer International Publishing: Cham, Switzerland, 1992; pp. 329-364.

88. Wang, Z.; Kumar, A.; Sevilla, M.D.; Zeng, X. Anaerobic oxidation of methane to methyl radical in $\mathrm{NTf}_{2}$-based ionic liquids. J. Phys. Chem. C 2016, 120, 13466-13473. [CrossRef]

89. Chaudoy, V.; Ghamouss, F.; Luais, E.; Tran-Van, F. Cross-Linked polymer electrolytes for li-based batteries: From solid to gel electrolytes. Ind. Eng. Chem. Res. 2016, 55, 9925-9933. [CrossRef]

90. Willem, L.; Driessen, J.; Dunbar, K.; Pence, L. Solid solvates: The use of weak ligands in coordination chemistry. Inorg. Synth. 1992, 29, 111-118.

91. Zhang, J.X.J.; Hoshino, K. Molecular Sensors and Nanodevices 2e: Principles, Designs and Applications in Biomedical Engineering, 2nd ed.; Elsevier Science \& Technology: San Diego, CA, USA, 2018.

92. Fleischer, M.; Meixner, H. Sensitive, selective and stable $\mathrm{CH}_{4}$ detection using semiconducting $\mathrm{Ga}_{2} \mathrm{O}_{3}$ thin films. Sens. Actuators B Chem. 1995, 26, 81-84. [CrossRef]

93. Otagawa, T. Electrochemical oxidation of methane in nonaqueous electrolytes at room temperature. J. Electrochem. Soc. 1985, 132, 2951. [CrossRef]

94. Hsieh, S.Y. Anodic oxidation of methane. J. Electrochem. Soc. 1977, 124, 1171. [CrossRef]

95. Weingärtner, H. An introduction to aqueous electrolyte solutions. ChemPhysChem 2008, 9, 1482. [CrossRef]

96. Ashcroft, A.; Cheetham, A.; Green, M. Partial oxidation of methane to synthesis gas using carbon dioxide. Nature 1991, 352, 225-226. [CrossRef]

97. Wang, Z.; Guo, M.; Baker, G.A.; Stetter, J.R.; Lin, L.; Mason, A.J.; Zeng, X. Methane-oxygen electrochemical coupling in an ionic liquid: A robust sensor for simultaneous quantification. Analyst 2014, 139, 5140-5147. [CrossRef] [PubMed]

98. Mu, X.; Wang, Z.; Guo, M.; Zeng, X.; Mason, A.J. Fabrication of a miniaturized room temperature ionic liquid gas sensor for human health and safety monitoring. In Proceedings of the 2012 IEEE Biomedical Circuits and Systems Conference (BioCAS), Zhubei City, Taiwan, 28-30 November 2012.

99. Rehman, A.; Zeng, X. Ionic liquids as green solvents and electrolytes for robust chemical sensor development. Acc. Chem. Res. 2012, 45, 1667-1677. [CrossRef] [PubMed]

100. Dosi, M.; Lau, I.; Zhuang, Y.; Simakov, D.S.A.; Fowler, M.W.; Pope, M.A. Ultra-sensitive electrochemical methane sensors based on solid polymer electrolyte-infused laser-induced graphene. ACS Appl. Mater. Interfaces 2019, 11, 6166-6173. [CrossRef] [PubMed] 
101. Carter, M.T.; Stetter, J.R.; Findlay, M.W.; Patel, V. Printed amperometric gas sensors. ECS Trans. 2013, 50, 211-220. [CrossRef]

102. Yao, S.; Stetter, J.R. Solid Electrolyte Sensors for Emissions Monitoring; BCPS Department, Chemistry, Illinois Institute of Technology: Chicago, IL, USA, 2012.

103. Nádherná, M.; Opekar, F.; Reiter, J. Ionic liquid-polymer electrolyte for amperometric solid-state NO2 sensor. Electrochim. Acta 2011, 56, 5650-5655. [CrossRef]

104. Narayanan, B.K.; Akbar, S.A.; Dutta, P.K. A phosphate-based proton conducting solid electrolyte hydrocarbon gas sensor. Sens. Actuators B Chem. 2002, 87, 480-486. [CrossRef]

105. Alberti, G.; Carbone, A.; Palombari, R. Solid state potentiometric sensor at medium temperatures $\left(150-300^{\circ} \mathrm{C}\right)$ for detecting oxidable gaseous species in air. Sens. Actuators B Chem. 2001, 75, 125-128. [CrossRef]

106. Wang, Z.; Zeng, X. Bis(trifluoromethylsulfonyl)imide $\left(\mathrm{NTf}_{2}\right)$-Based ionic liquids for facile methane electro-oxidation on Pt. J. Electrochem. Soc. 2013, 160, H604-H611. [CrossRef]

107. Yin, H.; Wan, H.; Lin, L.; Zeng, X.; Mason, A.J. Miniaturized planar RTIL-based electrochemical gas sensor for real-time point-of-exposure monitoring. In Proceedings of the 2016 IEEE Healthcare Innovation Point-Of-Care Technologies Conference (HI-POCT), Cancun, Mexico, 9-11 November 2016.

108. Wan, H.; Yin, H.; Lin, L.; Zeng, X.; Mason, A.J. Miniaturized planar room temperature ionic liquid electrochemical gas sensor for rapid multiple gas pollutants monitoring. Sens. Actuators B Chem. 2018, 255, 638-646. [CrossRef]

109. Sekhar, P.K.; Kysar, J.; Brosha, E.L.; Kreller, C.R. Development and testing of an electrochemical methane sensor. Sens. Actuators B Chem. 2016, 228, 162-167. [CrossRef]

110. Gross, P.A.; Jaramillo, T.; Pruitt, B. Cyclic-Voltammetry-Based Solid-State Gas Sensor for Methane and Other VOC Detection. Anal. Chem. 2018, 90, 6102-6108. [CrossRef]

111. Yang, B.; Xu, J.; Wang, C.; Xiao, J. A potentiometric sensor based on $\mathrm{SmMn}_{2} \mathrm{O}_{5}$ sensing electrode for methane detection. Mater. Chem. Phys. 2020, 245, 122679. [CrossRef]

112. Favard, A.; Yan, X.; Anguille, S.; Moulin, P.; Seguin, J.L.; Aguir, K.; Bendahan, M. Sensors \& transducers humidity impact reduction on WO 3 gas microsensor response using new filters based on ionic liquid. In Proceedings of the Third International Conference on Advances in Sensors, Rome, Italy, 25-29 March 2018.

113. Vasiliev, A.A.; Varfolomeev, A.E.; Volkov, I.A.; Simonenko, N.P.; Arsenov, P.V.; Vlasov, I.S.; Ivanov, V.V.; Pislyakov, A.V.; Lagutin, A.S.; Jahatspanian, I.E.; et al. Reducing humidity response of gas sensors for medical applications: Use of spark discharge synthesis of metal oxide nanoparticles. Sensors 2018, 18, 2600. [CrossRef] [PubMed]

114. Wang, H.; Zhang, W.; You, L.; Yuan, G.; Zhao, Y.; Jiang, Z. Back propagation neural network model for temperature and humidity compensation of a non-dispersive infrared methane sensor. Instrum. Sci. Technol. 2013, 41, 608-618. [CrossRef]

(C) 2020 by the authors. Licensee MDPI, Basel, Switzerland. This article is an open access article distributed under the terms and conditions of the Creative Commons Attribution (CC BY) license (http://creativecommons.org/licenses/by/4.0/). 